\title{
On orbit measurement of response vs. scan angle for the infrared bands on TRMM/VIRS
}

\author{
William L. Barnes ${ }^{\mathrm{a}}$, Cheng-Hsuan Lyu ${ }^{\mathrm{b}}$, and Robert A. Barnes ${ }^{\mathrm{c}}$ \\ ${ }^{a}$ Laboratory for Hydrospheric Processes, Goddard Space Flight Center, Greenbelt, \\ MD 20771 \\ ${ }^{\mathrm{b}}$ Caelum Research Corporation, Greenbelt, MD 20771 \\ 'SAIC General Sciences Corporation, Laurel, MD 20705
}

\begin{abstract}
The Visible and Infrared Scanner on the Tropical Rainfall Measuring Mission (TRMM/VIRS) is a whiskbroom imaging radiometer with two reflected solar bands and three emissive infrared bands. All five detectors are on a single cooled focal plane. This configuration necessitated the use of a paddlewheel scan mirror to avoid the effects of focal plane rotation that arise when using a scan mirror that is inclined to its axis of rotation. System radiometric requirements led to the need for protected silver as the mirror surface. Unfortunately, the SiOx coatings currently used to protect silver from oxidation introduce a change in reflectance with angle of incidence (AOI). This AOI dependence results in a modulation of system level response with scan angle. Measurement of system response vs. scan angle (RVS) was not difficult for the VIRS reflected solar bands, but attaining the required accuracy for the IR bands in the laboratory was not possible without a large vacuum chamber and a considerable amount of custom designed testing apparatus. Therefore, the decision was made to conduct the measurement on-orbit.

On three separate occasions, the TRMM spacecraft was rotated about its pitch axis and, after the nadir view passed over the Earth's limb, the VIRS performed several thousand scans while viewing deep space. The resulting data has been analyzed and the RVS curves generated for the three IR bands are being used in the VIRS radiometric calibration algorithm. This, to our knowledge, the first time this measurement has been made on-orbit. Similar measurements are planned for the EOS-AM and EOS-PM MODIS sensors and are being considered for several systems under development.

The VIRS on-orbit results will be compared to VIRS and MODIS system level laboratory measurements, MODIS scan mirror witness sample measurements and modeled data.

Keywords: VIRS, on-orbit calibration, spacecraft maneuvers, reflectance, infrared, imaging radiometry
\end{abstract}




\section{GSFC STI PUBLIC DISCLOSURE EXPORT CONTROL CHECKLIST}

The Export Control Office requests your assistance in assuring that your proposed disclosure of NASA scientific and technical information (STI) complies with the Export Administration Regulations (EAR, 15 CFR 730-774) and the International Traffic In Arms Regulations (ITAR, 22 CFR 120-130). The NASA Export Control Program requires that every domestic and intemational presentation/publication of GSFC STI be reviewed through the GSFC Export Control Office in accordance with the NASA Form 1676 NASA Scientific and Technical Document Availability Authorization (DAA) process. Release of NASA information into a public forum may provide countries with interests adverse to the United States with access to NASA technology. Failure to comply with the ITAR regulations and/or the Commerce Department regulations may subject you to fines of up to $\$ 1$ million and/or up to ten years imprisonment per violation. Completion of this checklist should minimize delays in approving most requests for presentation/publication of NASA STI.

Generally, the export of information pertaining to the design, development, production, manufacture, assembly, operation, repair, testing, maintenance or modification of defense articles, i.e., space flight hardware, ground tracking systems, launch vehicles to include sounding rockets and meteorological rockets, radiation hardened hardware and associated hardware and engineering units for these items are controlled by the State Department under the ITAR. A complete listing of items covered by the ITAR can be accessed at http://gsfc-bluenun.gsfc.nasa.gov/export/regsitar.htm. The export of information with respect to ground based sensors, detectors, high-speed computers, and national security and missile technology items are controlled by the U.S. Commerce Department under the EAR. If the information intended for release falls within the above categories but otherwise fits into one or more of the following exemptions, the information may be released.

\section{EXEMPTION 1}

If your information is already in the public domain in it's entirety through a non-NASA medium and/or through NASA release previously approved by the Export Control Office, the information is exempt from further review. If the information falls into this category, you may attest that you are using this exemption by signing below.

Signature

Date

\section{EXEMPTION II}

If your information pertains exclusively to the release of scientific data, i.e. data pertaining to studies of clouds, soil, vegetation, oceans, and planets, without the disclosure of information pertaining to articles controlled by the ITAR or EAR, such as flight instruments, high speed computers, or launch vehicles, the information is exempt from further review. If the information falls into this category, you may attest that you are using this exemption by signing below.
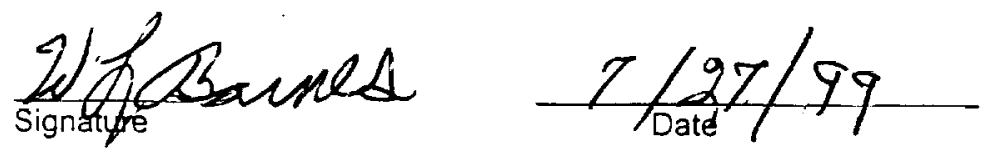

\section{EXEMPTION III}

If your information falls into the areas of concern as referenced above, but is offered at a general purpose or high level, i.e. poster briefs and overviews, where no specific information pertaining to ITAR or EAR controlled items is offered, the information is exempt from further review. If the information falls into this category, you may attest that you are using this exemption by signing below. 


\section{EXEMPTION IV}

If your information is not satisfied by the 3 exemptions stated above, the information may be released using exemption 125.4(b)(13) of the ITAR. Use of this exemption is afforded only to agencies of the Federal Government and allows the release of ITAR controlled information into the public domain. But the GSFC Export Control Office has determined that use of this exemption will be allowed only after we receive assurance that such release is a responsible action. To this end, an internal guideline has been established pursuant to the use of this exemption: That the information does not offer specific insight into design, design methodology, or design processes of an identified ITAR controlled item in sufficient detail (by itself or in conjunction with other publications) to allow a potential adversary to replicate, exploit and/or defeat controlled U.S. technologies. All signatures of approval on NASA Form 1676 expressly indicate concurrence with the responsible use of Exemption IV when Exemption IV has been cited by the author. If you determine that you have met this criteria, you may attest your determination by signing below, and the GSFC Export Control Office will offer favorable consideration toward approving your presentation/publication request under this special exemption.

Signature

\section{Date}

If you do not satisfy the above exemptions, please contact the GSFC Export Control Office for further clarification on the releasability of your information under the ITAR or EAR. 


\section{0-24 September 1999 \\ University of Florence, Italy}

\author{
Symposium Chairs: \\ Hatem Nasr, Baker Hughes, Houston, Texas USA \\ Luca Pantani, CNR-IROE, Florence, Italy
}

Symposium Co-Chair:

Enzo Pranzini, University of Florence, Italy

\section{Sponsored by}

University of Florence, Italy - Department of Earth Science

EOS - The European Optical Society

SPIE - The International Society for Optical Engineering

CNR - The National Research Council of Italy

NASA - National Aeronautics and Space Admlnistration,

SIOF - Italian Society of Optics and Photonics.

\section{Invitation to Attend}

A few decades ago aerial photography, phótogrammetry, and radio ionospheric studies gave birth to the field of remote sensing, with some of the most dramatic developments occurring during World War ll. Various national space programs helped evolve the technology into what it is today and made it a viable tool for environmental monitoring and other very practical applications. Today, remote sensing is one of the fastest growing technologies around. It is a multibilition dollar industry and remote thematic images are routinely used in an increasing number of fields. Remgte sensing data has evep become part of our daily lives. Weather satellites are the primary source for weather forecasting. Satellite data is being used today for crop forecasting, Fining and exploration, archeological discoveries, and even real estate development, to name few. This was almost unimagined a couple of decades ago. In the next millenium, as the technology continues to evolve, we will witriess an even faster growth of remote sensing applications and commerce.

Today, there are very few yearly conferences on Remote Sensing that offer a comprehensive coverage of scientific topics, applications, sensors, systems and satellite platforms. The EUROPTO Symposium is one such conference. The EUROPTO Symposium also brings a unique blend of international participants, where over 20 countries have been represented every year. The remote sensing community has four main participants:

- Scientists, who research new sensors, data processing techniques, phenomenology, and applications;

- Industry, which develops new platforms and sensors and engages in the commerce of remote sensing technology;

- Users, who employ remote sensing products for their daily needs;

- Governments, which want to develop the technology to improve and protect their societies and promote commerce.

We invite participants from all these communities to participate in our next EUROPTO Symposium on Remote Sensing in Florence, Italy, 20-24 September 1999. This Symposium is the sixth in this series. We continue to improve on this meeting. Lastyear's yery successful Symposium in Barcelona attracted about 400 participants. This will be a unique forum to gét informed and debate the state of the art of the technology: sensors, platforms, and applications.

Eleven conferences will be held in the framework of the Symposium. Each conference will include oral presentations and posters. We warmly invite you to participate in the EUROPTO Symposium on Remote Sensing. We are working hard to máke it a symposium of the highest quality.

\section{Hatem Nasr}

Baker Hughes, Houston, Texas

L.....

Luca Pantanl

CNR-IROE "Nello Carrara", Florence, Italy
Including:
- Atmospheric Sensing
- Earth Surface Sensing
- Platforms and Systems

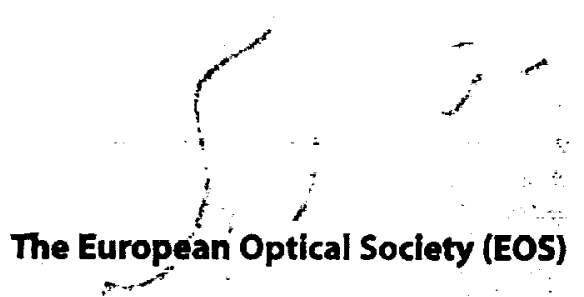

The purpose of the EOS is to contribute to progress in optics and related sciences and to promote applications at a European and international level by bringing together legal and natural persons active in these. disciplines and their applications. It is also a non-profit society.

\section{SPIE - The International Society for Optical Engineering}

SPIE is a non-profit society dedicated to advancing engineering and scientific applications of optical, electro-optical, and optoelectronic instrumentation, systems? and technology. Its members are scientists, engineers, and users interested in the reduction to practice of these technologies. SPIE provides the means for communicating new developments and publications to the scientific, engineering, and user cómmunities through its publications and symposia.

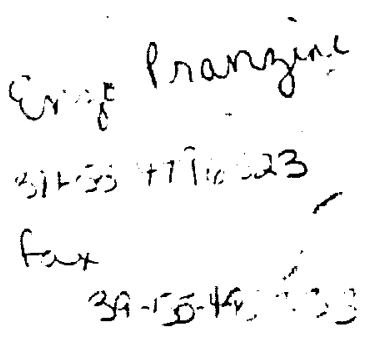


Conference Chairs: U. Schreiber, TU Munich, Koetzing, Germany, Ch. Werner, DLR, Oberpfaffenhofen, Germany

Conference Co-Chairs: K. Asai, Tohoku Institute of Technology, Sendai, Japan; P. Ingman, ESAESTEC, Noordwijk, The Netherlands; P. Flamant, CNRS, Palaiseau, France; $M$. Huffacker, CTI, Lafayette, CO USA; M. Kavaya, NASA, Huntsville, AL USA; G. Matvienko, IAO, Tomsk, Russia; N. Sugimoto, NIES, Ibaraki, Japan; I. Prochazka, TU Prag, Tchech Republic; John Degnan, NASA Greenbelt, MD USA; G. Bianco, ASI, Matera, Italy; D. Winker, NASA, Langley, MD USA

The major interest of this conference is focused on Satellite / Lunar Laser Ranging (S/LLR) and Atmospheric Lidar.SLR contributed a lot to the earth sciences over the last two decades, enhancing the resolution of the measured ranges continuously. Nowadays the domain below one centimetre has been reached. Therefore, the structure of the targets and the rapidly changing propagation properties of the atmosphere and a high level of system stability have become relevant. Multiple sensor models, near real-time data consistency checks in clustered stations and in situ measurements of atmospheric parameters via remote sensing techniques are becoming keywords of a $\mathrm{mm}$ - level SLR community.

There are a lot of similarities between SLR and lidar, beginning from the laser radar technique and ending in the application for atmospheric monitoring or correction. Tomography is a new technique that can be applied from ground stations using retro- reflectors in space or from space using hard targets on the ground. There are lidars or laser radars in orbit. Results of these sensors and discussions of planned missions are the goal of the second part of the conference.

The conference will be the continuation of the Europto London conference in 1997 and is aimed to be a market for ideas. The session chairs are advised to stimulate the discussion. Therefore the number of accepted papers is limited to relevant new material and one or two invited papers. It is planned to provide time for extended discussions (accompanied with wine and cheese) to trade ideas or to present problems for discussions.

For the atmospheric propagation conference again a joint session is scheduled on the multiple scattering aspect.

\section{For more information e-mail:}

christian.werner@dlr.de schreiber@wettzell.ifag.de

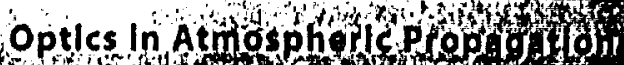

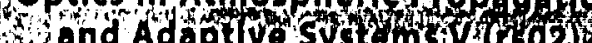

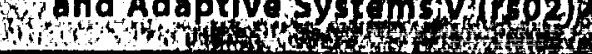

Conference Chairs: Anton Kohnle, FGAN Forschungsinstitut für Optik, Tübingen, FR Germany; John D. Gonglewski, Philips Laboratory, Kirkland AFB, New Mexico, USA

Conference Co-Chairs: Luc R. Bissonnette, Defence Research Establishment, Valcartier Canada; Piero Bruscaglioni, University of Florence, Florence, Italy; J. Christopher Dainty. Imperial College of Science, London, United Kingdom; Adam D. Devir, EORD, Technion, Haifa, Israel; Marc Séchaud, ONERA, Paris, France; Mikhail A. Vorontsov, U.S. Army Research Labs., Adelphi, MD USA

The use of satellites and high elevated platforms for active and passive remote sensing of earth and its atmosphere, as well as for high resolution imaging of ground-based and airborne objects, is a field of growing interest from civilian and military perspectives. Different sophisticated systems are currently used or scheduled for deployment for the purpose of covering the spectral regions from UV to $C M$ waves. The measurement analysis depends crucially on the thorough understanding of all optical effects that limit the sensor performance through an atmosphere that acts as an absorbing, scattering, and radiating random medium.

High resolution space to ground (or ground to space) imaging is very much dependent on the long path geometries involved, especially due to altitude-dependent atmospheric propagation parameters and different radiating backgrounds.

Papers are solicited on the following and related topics:

- Imaging (band, spectral and hyperspectral) of ground-based and airborne objects from space and vice versa;

- Techniques for mitigation of atmospheric effects on imaging: adaptive optics, deconvolution, sensor fusion, post processing etc;

- Propagation and imaging through inhomogeneous dense media; multiple scattering effects on LIDAR and imager performance;

- Propagation and imaging through optical turbulence, including strong turbulence regimes;

- Propagation models and correction methods for atmospheric effects in remote sensing:

- Statistics of propagation parameters, statistics of cloud free line of sights, etc. Effects of depolarisation, pulse stretching. loss of coherence for active (laser) systems;

- Characterisation of the propagation environment: profiles of temperature, humidity, extinction, refractivity, radiance (also non-LTE), optical turbulence; updates of transmission and radiance codes.

A special session is planned to combine this conference with the conference on Laser Radar Techniques. The session will be dedicated to multiple scattering effects with respect to laser propagation and backscattering.
Conference Chair: Jacqui Russel, Imperial College, London, United Kingdom

All aspects of the remote sensing of clouds and the atmosphere is the focus of this conference but special emphasis will be placed on:

- High spectral resolution observations

- Polarised measurements and their interpretation

- Radar and passive microwave measurements

- Lidar measurements

Topics will include:

- Cloud detection and characterization

- Cirrus

- Scattering and absorption by nonspherical particles

- Temperature and humidity profiling

- Lidar, microwave and radar measurements

- Inversion problems and techniques

- Remote sensing of ozone, aerosols, and trace gases

- Earth radiation budget

- Sensor systems and requirements for future satellites 
Conference Chairs: Edward W. Taylor, Air Force Research Lab, USA, Francis Berghmans, SCK CEN, Mol, Belgium

Program Committee: $H$. Thienpont, Vrije Universiteit, Brussels, Belgium; Marc Decreton, SCK-CEN, Brussels, Belgium, Marco Van Uffelen, Roger Greenwell Science Engineering Associates, USA; Tracy D. Hudson, US Army Aviation and Missile Command, USA; Joseph Suter, Johns Hopkins Applied Physics Lab, USA; Charles Barnes, Jet Propulsion Laboratory, USA; Karl Gill, CERN, Switzerland; Michael Watson, NASA Marshall Space Flight Center, Greenbelt, MD USA; Steven D. Pearson, NASA Marshall Space Flight Center, Greenbelt, MD USA; Marek Osinski, University of New Mexico, USA

The objective of this conference is to bring together researchers, component developers and systems designers currently addressing the application, functionality, survivability, endurability, and cost effectiveness of photonic technologies in radiation environments.

The rapid growth and implementation of fiber optics and photonic devices in commercial and military systems has evolved to the stage of several recent demonstrations and applications in space and enhanced radiation environments. Specific applications of photonics in radiation environments found in nuclear reactors and those of importance to satellite systems will be the theme and focus of this Conference. New and emerging photonic materials, components and systems that are under study or contemplated near term applications to improve or replace traditional electronics based sensors, processors, correlators, data links, trackers, communications and other military and commercial technologies are encouraged for presentation at this Conference.

Photonic systems and components such as laser diodes, light emitting diodes, vertical cavity surface emitting lasers, detectors, organic and inorganic modulators, integrated optic devices and spatial light modulators, as well as optical couplers, fiber optic amplifiers, optical fibers and other photonic innovations contemplated for space and reactor applications must be understood and quantified for their responses in the natural space and enhanced radiation environments. Authors are encouraged to present papers on new applications and research directions, advanced component and system developments as well as experimentation and theoretical modeling for understanding radiation induced effects in photonic materials and components.

Papers are solicited on the following and related example topics:

- planned and proposed photonics and fiber optics nuclear reactor and space experiments.

- Quantification and qualification of photonic systems, materials and component responses in radiation environments

- modeling of radiation environments-photonic responses

- MEMS-MOEMS system and component radiation effects studies

- optical interconnects and optical bus architectures for space systems

- advances in photonic materials suitable for radiation applications

- research emphasizing FO components and systems.
Conference chair: Joan Lurie, Datron/Transco, Inc., Hermosa Beach, CA USA

Program Committee: Richard Genet, Marconi Integrated Systems (formerly GDE Systems);

Gary Gnauck, Datron/Transco; Jacques

Huyghe, PLAN; Stephen Lutton, Core Software

Technology: Craig Molander, PCI Geomatics; Timothy Puckorius, Orbimage.

Over the next several years new satellite imaging systems, many launched by commercial companies, will collect remotely sensed data of differing resolutions in a variety of spectral bands. An unprecedented quantity and quality of data will be commercially available in a very short time after acquisition.

The potential utility of the data for solving a wide variety of problems is unquestioned but, in many cases, the commercial viability is unproven. This data is only useful (and the systems producing it commercially viable) if products derived from it can be shown to be readily understandable by the user and lead to enhanced profitability. Tools to convert imagery to information will be play a crucial role in the commercial marketplace. Equally important will be the ability to store and distribute the data in a timely manner. Another issue is the potential use of multiple data types (e.g. high resolution panchromatic and multispectral) to solve problems.

The object of this conference is to address the field of commercial remote sensing and help clarify market issues, commercial utility of remotely sensed data and data products, and associated legal issues. There will be sessions on space systems, on ground station technology to facilitate commercial use of data, on tools and on applications. Abstracts may address a wide range of subjects but should focus on the commercial aspects. Suggested topics include:

- Satellite systems for commercial remote sensing

- Tools which facilitate product generation for the commercial market place

- Data fusion tools

- Archiving and distribution tools

- "Exploitation" tools to extract information from imagery

- Ground stations - how to adapt to commercial customer requirements

New stations

Upgrades to existing stations

Legal issues, licenses, liability

- Commercial Applications - what is the market and what are the products?

- Agriculture

- Communications

- Real Estate

- Insurance

Forestry
Microelectronic

Manufacturing Technologies

19-21 May 1999

Caledonian Hotel

Edinburgh, United Kingdom

Abstract Due date: 7 October 1998

Manuscript Due date: 12 February $1 \subseteq$

\section{Optical System Design and Production}

\section{5-28 May 1999}

Technical University of Berlin

Berlin, Germany

Abstract Due date: 26 October 1998

Manuscript Due date: 26 April 1999

\section{Industrial Lasers and Inspection}

14-18 June 1999

Munich, Germany

Abstract Due date: 27 November 199

Manuscript Due date: 17 May 1999

\section{Envirosense}

14-18 June

Munich, Germany

Abstract Due date: 27 November 199. Manuscript Due date: 17 May 1999

\section{Remote Sensing}

20-24 September 1999

University of Florence

Florence, Italy

Abstract Due date: 8 March 1999

Manuscript Due date: 23 August 199؟ 


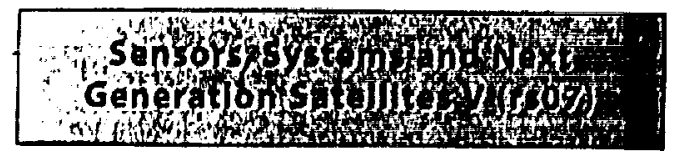

Conference Chair: Hiroyuki Fujisada, Science

University of Tokyo, Noda, Chiba, Japan

Conference Co-Chairs: S. P. Neeck, NASA/GSFC, Greenbelt, MD USA; H. Shimoda, Tokai Univ., Tokyo, Japan; G. Ceruti-Maori, Aerospatiale, Cannes La Bocca, France; R. Meynart, ESTEC, Noordwijk, Netherlands; R. Somma, Alenia Aerospaz io S.p.A., Rome, Italy; E. Sein, Matra Marconi Space, Toulouse, France; P. N. Slater, University of Arizona, Tucson, AZ USA

Many new remote sensing programs are under way throughout the world, specifically by U.S. European countries and Japan. NASA's office of Earth Science Enterprise (ESE) is developing plans for a series of programs including EOS Landsat, Earth System Science Pathfinder (ESSP), and New Millenium Earth Orbiting flight. Japanese NASDA has a series of ADEOS and ALOS programs. ESA has ENVISAT and METOP programs. Each of these programs is developing a set of remote sensing systems to address their science objectives.

Papers are solicited on the following and related topics:

- Sensors being developed.

- Satellites being developed.

- Technologies required to enable these sensors and satellites.

- New design concepts of sensors, systems and satellites.

- Hyper spectral sensors in space.

- Sensor calibration techniques.

- Modeling and simulation techniques for sensor concept development.

- Focal plane assemblies including detectors and spectral filters.

- Space cryogenics

- System precursors including test beds and airborne simulators.

- Data system being developed.

- New data processing techniques.

Sessions on the following topics are being planned:

ADEOS/ALOS mission and technologies.

- ENVISAT/METOP mission and technologies.

- ESE mission and technology

- New satellite technologies (navigation, on-board data processing, cooling system, etc.).

- Calibration.

- Hyper spectral sensors (mission analysis, design, performance, technologies, airborne sensors, etc.).
Conference Chairs: Ted Engman, NASA-GSFC, Greenbelt, MD USA

Conference Co-chairs: G. D'Urso, University of Napoli "Federico II" Napoli, Italy; Jesus Gonzalo de Grado, Ingegnaria y Servicios Aerospaciales, SA, Madrid, Spain, Mario Caetano, Centro Nacional de Informacao Geografica, Lisboa, Portugal

Remote sensing has been responsible for major advances in our understanding and ability to manage agriculture, forestry and water resources. In spite of this progress there are still many areas where the potential of remote sensing has not been fully realized and these are areas of active research. Much of the new research is directly related to the development of new sensors and an improved understanding of what the sensors are actually measuring as well as new and improved analysis techniques.

This session seeks papers on new applications of remote sensing and recent research results in agriculture, forestry, and hydrology.

Contributions using visible, near and far infrared, thermal infrared and microwave measurements are requested, but special consideration will be given to papers addressing use of satellite data or proposing synergism of different sensors.

Papers are requested that address the following and related topics:

- Agriculture, including crop yield modeling, early warning, disease and insect damage, drought effects, crop monitoring at regional and global scales, radiative transfer modeling of vegetation canopies, and related topics;

- Ecosystems, including forest management, biomass estimates, LAI/FPAR products, vegetation indices, land cover products, fires, deforestation, urban ecosystems, radiative transfer modeling of ecosystem properties, and related topics;

- Hydrology including parameterization of regional and macro hydrological models, water resource monitoring, estimates of latent and sensible heat, snow, soil moisture, urban hydrology, water quality, sedimentation, and erosion, and related topics;
Conference Chair: Sebastiano Serpico, University of Genoa, Italy

Conference Co-chairs: J. A. Benediktson, Iceland, Iceland; C. H. Chen, Univ. of Massachussets at Dartmouth, USA; J. Desac Univ. Paul Sabatier, Toulouse, France; $M$. Pet Univ. of Surrey, United Kingdom

Scientific Committee: E. Binaghi, CNR ITIM, Milan, Italy; I. Bloch, ENST, Paris, France; P. Blonda, CNR IESI, Bari, Italy; L. Bruzzone, Ur Genoa, Italy; M. Datcu, DLR, Oberpfaffenhof Germany; S.Dellepiane, Univ. of Genoa, Ital S. Fujimura, Univ. of Tokyo, Japan; I.

Kanellopoulos, JRC, Ispra, Italy; D. Landgre. Purdue University, USA; D. C. Mason, ESSC, University of Reading, United Kingdom; M. Migliaccio, University of Cagliari, Italy; J. Rasson, FUNDP Univ. Namur, Belgium; P.C.Sr JRC, Ispra, Italy

The main goal of this conference is to exam all aspects of image and signal processing $\mathrm{fc}$ remote image analysis and understanding. Papers describing recent and original work the following and related research topics ar: welcome:

- Signal and image enhancement and restoration

- Registration techniques

- Stereoscopic images analysis

- Shape and texture analysis

- Image segmentation and object recognit

- Multisensor and multisource techniques

- Data fusion

- Statistical, structural and hybrid pattern recognition techniques

- Integration of remotely sensed data and geodata

- Neural techniques

- Scene analysis and image understanding

- Knowledge-based image understanding

- Expert systems, fuzzy logic, and Al techni

Note:Those wishing to participate in this conference should prepare extended $500 \mathrm{w}$ abstracts on two A4 pages. All other abstrac submission instructions should be followed 


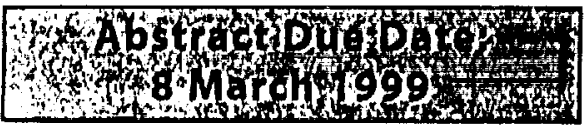

\section{YOUR ABSTRACT SHOULO INCLUDE:}

1. SUBMIT TO: Remote Sensing

Conference Title/Conference

Chair/Conference Code (rs01, rs02, etc.)

\section{ABSTRACT TITLE}

3. AUTHOR LISTING (principal author first) First (given) name Last (family) name, affiliation, mailing address, telephone, telefax, and e-mail address.

\section{CORRESPONDENCE FOR EACH AUTHOR}

5. PRESENTATION

Please indicate your preference for either "Oral Presentation" or "Poster Presentation". Placement is subject to chairs' discretion.

\section{KEY WORDS (3-5)}

7. ABSTRACT TEXT one full A4-page typed on white paper. The abstract should be divided into background, materials and methods, results, and discussion. Emphasize the main contribution of the work; the original contribution with respect to the state of the art; and include references to related papers from the same authors. Report your results in detail.

8. BRIEF BIOGRAPHY (principal author only) Approximately 50 to 100 words.

\section{CONDITIONS OF ACCEPTANCE}

- Authors are expected to secure travel and accommodation funding, independent of the organisers, through their sponsoring organisations before submitting abstracts.

- Only original material should be submitted.

- Commercial papers, description of papers, with no research content, and papers where supporting data or a technical description cannot be given for proprietary reasons will not be accepted for presentation in this symposium.

- Abstracts should contain enough detail to clearly convey the approach and the results of the research.

- Government and company clearance to present and publish should be final at the time of submittal.

- Applicants will be notified of acceptance by mail no later than 5 April 1999.

\section{PAPER REVIEW}

To ensure a high quality conference, all abstracts and Proceedings papers will be reviewed by the conference chairs for technical merit and content.

\section{ORAL OR POSTER PRESENTATION}

Instructions for Oral and Poster presentations will be included in your author kit. All Oral and Poster presentations are included in the Proceedings and require a manuscript.

Preliminary Registration Fees

With the introduction of the EURO in January 1990 conference fees will be charged in Euro's.

\begin{tabular}{|c|c|c|}
\hline & Euros & (Ref. only \\
\hline \multicolumn{3}{|l|}{ Authors: } \\
\hline EOS/SPIE Member & 325 & $(-\$ 380)$ \\
\hline Nonmember & 375 & $(-\$ 439)$ \\
\hline \multicolumn{3}{|l|}{ Attendees: } \\
\hline EOS/SPIE Member & 400 & $(\sim \$ 468)$ \\
\hline Nonmember & 450 & $(\sim \$ 527)$ \\
\hline \multicolumn{3}{|l|}{ Students: } \\
\hline EOS/SPIE Member & 150 & $(\sim \$ 176)$ \\
\hline Nonmember & 200 & $(\sim 234)$ \\
\hline
\end{tabular}

Registration fee includes technical sessions, coffee breaks, reception, and 1 Proceedings volume for all but student fees.

or mail three copies of your abstract to: Remote Sensing

Boulevard St. Michel 15

B-1040 Brussels

Belgium

- or fax one copy to +32-2-7431550 (send each abstract separately).

\section{PUBLISHING POLICY}

Manuscript due dates must be strictly observed. Whether the conference volume will be published before or after the meeting, late manuscripts run the risk of not being published in the Proceedings. The objective of this policy is to better serve the conference participants and the technical community at large.

Your cooperation in supporting this objective will be appreciated by all.

\section{PROCEEDINGS}

These meetings will result in published Proceedings available for order through the Advance Programme. Manuscripts are required of all accepted applicants and must be submitted in English by 23 August 1999. Copyright to the manuscript is expected to be released for publication in the conference Proceedings. Note: If an author does not attend the meeting and make a presentation, the chair may choose not to publish the author's manuscript in the conference volume. Papers published are indexed in leading scientific databases including INSPEC. Compendex Plus, Physics Abstracts, Chemical Abstracts, International Aerospace Abstracts and Index to Scientific and Technical Proceedings.

\section{ORAL PRESENTATION}

Each author is generally allowed 15 minutes plus a five-minute discussion period. The following media equipment is provided free of charge: $35 \mathrm{~mm}$ slide projectors, overhead projectors, and flipcharts. Video and other equipment may be provided upon request.

\section{AUTHOR BENEFITS}

Authors and co-authors are expected to pay a reduced registration fee. Included with a fee payment is a copy of the Proceedings volume in which the participant's role or paper appears.

\section{Meeting Venue}

The symposium will be held at:

University of Florence

Department of Earth Science

Via Giorgio Lapira 4

1-50139 Florence

Italy

\section{Accommodation}

Hotel Accomodations will be handled by the EUROPTO ${ }^{\circ}$, Series staff. More information will be ava lable in the Technical Programme.

\section{The City of Florence}

Italy is the holder of $40 \%$ of the world's artistic and historical treasures; $26 \%$ of these are in Florence. It is beautiful open sky museum where magnificient Italic Renaissance masterpieces can be discovered in ever corner, day by day: Leonardo, Michelangelo, Raffaello Tiziano, and many others can be admired through a short and pleasant walk, a few minutes from the conference citadel.

Florence is also a busy cosmopolitan centre which offers in every season of the year many traditional musical and theatre festivals, historic cafés, excellent restaurants with international standards as well as typical picturesque "trattorie" serving the best region Italian cuisine.

Fascinating excursions take the visitors to beautiful a cities of Tuscany such as Pisa, Lucca, and Siena. 